\title{
LAS COMUNIDADES Y LA COMUNIDAD DE VILLA Y TIERRA DE CUELLAR
}

352 (091) (46. Cuéllar)

\author{
por \\ Esteban Corral García \\ Secretario de primera categoría de Administración local
}

SUMARIO: I. ORIGEN DE LAS COMUNIDADES: 1. LA REPOBLACION DEL Duero. 2. La Repoblación entre el Duero y el TaJo. 3. Opinión de LOS AUTORES SOBRE EL ORIGEN DE LAS COMUNIDADES.-II ORIGEN DE LA COMUNIDAD DE CUELLAR.-III. MUNICIPIO Y COMUNIDAD: 1. Concepto. 2. Caracteres. 3. Caracteres de la de Cúlllar. 4. NATURALEZA Y PERSONALIDAD.-IV. ESTRUCTURA: VILLA Y ALDEAS. VINCULO Y SEXMOS.-V. EVOLUCION Y DISOLUCION: EVOLUCIÓN a TRAVÉS dE LAS LEYeS de RÉgIMEN LOCAL.-VI. SITUACION ACTUAL: 1. Repercusión de las Leyes desamortizadoras. 2. PersonaliDAD Y NATURALEZA.-VII. MANCOMUNIDADES Y COMUNIDADES.

\section{ORIGEN DE LAS COMUNIDADES}

1. La REPOBLACión DEL DUero

En el año 741 la rebelión de los bereberes, establecidos en Galicia, contra los árabes y su marcha hacia el Sur saqueándolo todo, un período de hambre del 750-775 lo aprovecha, en expediciones devastadoras, para exterminar lo que queda de la población musulmana y para repoblar su reino con mozárabes, que encuentra en las comarcas, Alfonso VI.

La cuenca del Duero queda así, al ser abandonadas las ciudades y aldeas y las explotaciones agrarias, totalmente despoblada y yer- 
ma porque las continuas correrías militares de árabes y cristianos, en opinión de SANCHEZ ALBORNOZ (1), la hicieron inhabitable. Hacia el 850 los cristianos comenzaron a avanzar por los territorios despoblados del valle del Duero. Ordoño I inició la repoblación de tierras incultas.

La repoblación del desierto del Duero se lleva a cabo por inmigrantes de la zona marítima y serrana (los que empezaron la $\mathrm{Re}$ conquista) y por los mozárabes que venían del Sur.

Se establecen en ella numerosos grupos de hombres libres, medianos o pequeños propietarios y enfiteutas de los dominios reales -continúa el autor citado- que sirven al Rey como soldados y le entregan rentas y tributos. Los Reyes, por otra parte, conceden tierras a gran número de nobles de sangre, que igualmente se convierten en soldados del Rey.

Surgen aldeas habitadas por estos hombres libres, enfiteutas del Rey y pequeños propietarios, no nobles, en régimen de economía agraria y ganadera. Es lógico pensar que en esta situación no podría haber Corte lujosa.

En tiempos de Fernán González nacen comunidades rivales autónomas, embriones de Municipios autónomos, con privilegio de inmunidad, en cuya virtud la entrada de funcionarios reales está totalmente vedada. En estas concesiones se halla el origen del Concejo castellano, tierras regidas por los Reyes y gobernadas en su nombre por «Comités». En la Castilla de los Condes éstos aceptan la autonomía sin regimiento ni funcionarios y los Concejos son gobernados por ellos mismos (2).

En el núcleo occidental de la Reconquista, la repoblación, según expone GaRcta DE Valdeavellano (3), pasa por cuatro etapas: 1. De repoblación monacal y privada. $2 .^{a}$ De repoblación concejil. 3. ${ }^{a} \mathrm{De}$ repoblación por Ordenes militares. 4. ${ }^{a}$ De repoblación a la vez concejil de Ordenes militares y nobiliarias.

A la repoblación privada corresponde la del valle del Duero; durante ella la acción colonizadora llegará hasta el curso del Duero, Arlanza y Pisuerga, alcanzando Salamanca y Sepúlveda después de la victoria de Simancas (año 940). Es en esta época cuando surge la villa de Cuéllar, «no șe sabe si por iniciativa del Conde de Mon-

(1) SANCHEZ Albornoz, España, un enigma histórico, Buenos Aires, 1962.

(2) SANCHEZ Albornoz, España, un enigma histórico, Buenos Aires, 1962.

(3) Garcta de Valdeavellano, Historia de las Instituciones, Madrid, 1968, pág. 239. 
zón o del Conde de Castilla» (4); tal es la conclusión a la que llega PÉREZ DE URBEL, basándose en los estudios de RUIZ AsENSIo.

La dificultad de repoblar el valle del Duero, la gran extensión de tierras desiertas, hizo que la repoblación privada fuera la más frecuente. Esta repoblación se lleva a cabo a través de dos formas (5): a) El «scalio», ocupación y aprehensión de la tierra, descuaje y rotulación de los yermos con o sin autorización del Rey. b) La "presura», ocupación de una tierra raíz sin dueño. Era la toma de posesión de la misma, sin que pueda precisarse si el dominio o la propiedad se adquiría por el transcurso del tiempo o en virtud de ciertos títulos.

Hasta el siglo xi los centros de población urbanos y rurales sólo fueron lugares de habitación y agrupaciones humanas cuya existencia no era reconocida por el Derecho, al substractum sociológico no acompaña el elemento político organizativo; eran ciudades o aldeas en el aspecto material sin ninguna organización jurídicopolítica de carácter local o municipal. Ni los castros romanos, ni los núcleos poblados rurales eran, antes de los siglos XI y XII, entidades jurídico-públicas. En una palabra, antes del siglo XI no existe el Municipio jurídicamente hablando. Cuéllar no es lógico pensar constituyera una excepción a esta regla. Se había producido su primera repoblación, pero no su nacimiento como Entidad municipal.

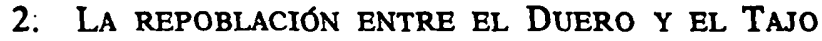

La repoblación entre el Duero y el Tajo, la de Cuenca y su tierra a fines del siglo XIr, la de Extremadura y la Mancha en el XIII, hicieron nacer una red fortísima de pequeños y grandes Concejos de realengo. A raíz de la conquista de Toledo, en 1805, surgen esta serie de grandes Concejos: Madrid, Segovia, Avila, Salamanca, etc., y Cuéllar. Tienen un centro urbano más o menos fuerte, mejor o peor fortificado, y su tierra, extensa y sembrada de aldeas. Estos Concejos -afirma SANCHEZ ALBORNOZ- están integrados por hom-

(4) Justo PÉRz DE URBeL, El Condado de Castilla, tomo II, pág. 126, referencia recogida en la pág. 79 de Historia de Cuéllar, de B. Velasco. Aunque su nombre no aparece en los documentos medievales del siglo $X$, no podemos dudar que su repoblación es simultánea a las villas cercanas de Peñafiel, Sacramenia y Sepúl. veda.

(5) Garcta de Valdeavellano, Historia de las Instituciones, Madrid, 1968, pág. 241. 
bres libres y son herederos de la sensibilidad política del pueblo de Castilla (6). Ayudan al Príncipe sobre todo en sus épocas difíciles, prestan guerreros y pagan tributos; a cambio de ello obtienen fueros y privilegios.

Surgen así las Comunidades o grandes Concejos con extensos términos municipales, con fuertes ciudadelas y núcleos amurallados, con aldeas sembradas a lo largo de su tierra, alfoz o áreas de influencia, con robustos castillos e iglesias, y cuyos pobladores son guerreros y pastores al tiempo. Todas estas afirmaciones son aplicables y demostrables en la Comunidad de Cuéllar.

Estas Comunidades concejiles se dividen toda la zona que enmarca el Duero y el Tajo y sirven de contrapeso a la aristocracia señorial y laical. Fueron cada vez más poderosas. Ningún señorío tuvo el poder militar y económico que ellas, hasta el punto de hacer Reyes, caso de las Comunidades de Avila, Segovia y Salamanca, con Fernando III, o mantenerlos (Cuéllar sirve, en los momentos difíciles de sus minorías, de sostén y apoyo a Fernando IV al asumir en 1295 doña María de Molina la tutela, convirtiéndose en centro de la vida política castellana) (7). De los Reyes se obtienen tributos y gabelas y apoyo frente a la aristocracia.

La madurez del régimen municipal provoca la plena autonomía y la desaparición de tenencias (cargos concedidos a nobles para intervenir en los Concejos).

Después de la conquista de Toledo, el esquema de organización municipal tenía más de un siglo, con un centro urbano cabeza de un término poblado de aldeas, autónomo y que el Rey regía a través del dominus villae, que termina por desaparecer, siendo entonces máxima su autonomía. Son éstos los grandes Concejos o Comunidades, que nacen en villas de importancia estratégica y que en ocasiones se hermanan y dotan a las aldeas de una organización embrionaria.

Del siglo $\mathrm{x}$ al xIII es su época de apogeo, sobre todo en los reinados de Fernando III y Alfonso $X$. La crisis económica comienza a partir de Alfonso $\mathrm{X}$, durante cuyo reinado la nobleza incrementa sus riquezas y los moros contraatacan, originando su decadencia.

(6) SANChez Albornoz, España, un enigma histórico. Nota citada por B. VELasco en Historia de Cuéllar, pág. 83, y por UbIETo ARTETa en Colección diplomdtica de Cuellar. Introducción.

(7) B. Veusco, Historia de Cuellar, Diputación provincial de Segovia, págs. 96 y siguientes. 
La autonomía desaparece a partir de Alfonso XI, con la institución de los Corregidores de nombramiento real y la aparición de los Regimientos. A partir de esta reforma - afirma SÁNCHEZ ALBORNOZ- los Concejos fueron sojuzgados y una minoría caballeresca se adueña del gobierno con exclusión del común del pueblo, que es reducido a silencio.

Los Regimientos caen en manos de viejos nobles del siglo XIII y de caballeros villanos olvidados de su origen.

La repoblación concejil corresponde a la habida entre el Duero y el Tajo. Se inicia durante el siglo XI, cuando se constituyen en Concejos o Municipios los centros de población. En esta nueva fase colonizadora la repoblación queda confiada a los Concejos de ciudades y villas del antiguo reino moro de Toledo y de la Extremadura o región fronteriza.

A estos Concejos (Avila, Segovia, Madrid, etc.) se les asigna un vasto territorio o alfoz, dependiente del Municipio, en el que las tierras incultas abundan, y la Comunidad procede a colonizar estableciendo nuevos poblados o "pueblos" en los que se asientan gentes libres que roturan y cultivan la tierra (8).

Los sistemas de repoblación que en esta segunda fase se utilizan son las cartas de población y las pueblas. Ya no se ocupan yermos, sino lugares. Las formas de asentamiento son: grupos rurales; la villa, que durante toda la época constituye la figura típica (grupo de edificios en torno a un patio o plaza central); las aldeas, que surgen en torno a una fuente o un río o por la atracción que ejerce un monasterio, el castillo y la ciudad.

Un estudio de la toponimia y de los topónimos de Cuéllar, de sus aldeas, muestra, como hemos visto, su origen medieval.

Repoblada la villa por segunda vez, el Concejo debió de ir estableciendo aldeas a lo largo de su alfoz; algunas, como Sanboal, surgen en torno a un monasterio ya existente en 1112. Otras, como Lobingos, Frumales, Viloria, existen ya en 1095. La mayoría tienen su origen en razón a su toponimia en la repoblación. La posibilidad de ocupar «tierras comunes o entradizas» debió ser un estímulo para el asentamiento.

En los siglos XI y XII las nuevas circunstancias económico-so. ciales dan lugar al renacimiento y crecimiento de las ciudades, obra de los mercaderes. Los centros rurales, al impulso de la sociedad

(8) Garcta de Valdeavellano, Historia de las Instituciones, Madrid, 1968, pág. 241. 
vecinal, derivado de la comunidad de habitación y de intereses, se constituyen en Comunidades locales.

La conclusión es que en los siglos XI y XIII las ciudades, por razones económicas, y los poblados, por comunidad de intereses organizados en Municipios, son ya órganos de la Administración local, y nos encontramos con dos tipos de Municipios: los Municipios urbanos, con autoridad sobre un extenso término municipal poblado de aldeas sometidas al gobierno de la ciudad o villa (las Comunidades), y los Municipios rurales, con escasa jurisdicción y limitada competencia.

3. OPINIÓN DE los aUtores SOBRE EL ORIGEN DE LAS COMUNIDADES

Resulta interesante recoger las opiniones, no siempre coincidentes, de los autores sobre estas Comunidades de Villa y Tierra, a las que MARÍN PÉREZ califica "como tan poco estudiadas, como ricas en peculiaridades y matices de gran interés para el jurista» (9).

- Hinojosa: «El Municipio en León y Castilla adquiere una amplia autonomía y libertad y régimen democrático. Asimismo, hacia la misma época medieval, los Municipios consiguen el derecho de asociarse para la realización de ciertos fines comunes y singularmente para la administración y defensa de sus bienes comunes destinados al disfrute del común de los vecinos».

Las considera como una manifestación del derecho de asociación y centra su acción principal en la administración y defensa de sus bienes (10). Esta concepción quizá sea más válida para el presente que para el pasado. Es cierto que el patrimonio constituye el fundamento básico de la Comunidad, pero no como fin en sí mismo, sino como medio para el cumplimiento de una serie de fines y competencias que se centran en el poder de la Villa, que en determinados momentos llega a ostentar un poder político, administrativo y jurisdiccional sobre la tierra. La aldea no está asociada, sino agregada y subordinada orgánica y jerárquicamente.

- Alvarez-Gendín "pone de manifiesto que es en el siglo XII, reinando Alfonso VII, cuando empiezan a surgir, apoderándose los Concejos de tierras, montes, etc., señoriales, consiguiendo su pro-

(9) UbIeto ARTeta, Colección diplomática de Cuéllar. Nota preliminar XIV. Diputación provincial de Segovia, 1961.

(10) Villar y Romero, ala Comunidad de Villa y Tierra de Santa María de Al. barracín», Estudios homenaje a Jordana de Pozas, pág. 222. 
piedad mediante fueros y cartas de población, así — dice - nació la Comunidad de Segovia. Otras veces se conceden a los pobladores por los antiguos señores bienes de realengo, señorío y abadengo. En ocasiones el otorgamiento consistió en tierras baldías, cuyo cultivo acometen los pueblos» (11).

El momento que ALVAREZ-GENDín señala como nacimiento es para SÁNCHEZ ALBORNOZ cuando comienza su crisis, cuyo inicio se produce con Alfonso $\mathrm{X}$, de pérdida de autonomía. Las Comunidades son los grandes Concejos que nacen de la repoblación entre el Duero y el Tajo; fruto de la repoblación concejil (12).

- Villar y Romero: «Tienen - dice- una larga historia cuyo origen se remonta a la Reconquista, tanto en León como en Castilla, y con caracteres no coincidentes en el reino de Aragón. Las Comunidades aragonesas se remontan a los últimos años del reinado de Alfonso el Batallador, hacia 1130. En Castilla su aparición es muy lejana, se remonta al siglo XII, enlazándose con la época de otorgamiento de fueros. Sin embargo, dice que con posterioridad a la Reconquista surgen otras (Cáceres y sus pueblos en el año 1479), el Asocio de la Universidad y Tierra de Avila, y Pedraza y su Tierra en Segovia, etc.» (13).

Tardío señala su nacimiento si seguimos la tesis de SÁNCHEZ Albornoz. Nos consta que Cuéllar y su alfoz, y no es de las más antiguas, existían en el siglo XI (14). En cualquier caso estas Comunidades tardías no creemos sean equiparables a las de la Extremadura castellana.

- LECCEA: «La necesidad hace nacer el Concejo reducido en principio a muy estrechos niveles y cerrado en sus muros. Con la Reconquista se adquieren territorios, bien por donación real, bien por derecho de conquista, y es. necesario poblarlos para que el enemigo no los oçupe, para desahogo de la población y para el cultivo. El medio de conseguirlo son las Cartas Pueblas dadas por los Reyes o por los Concejos».

Las Comunidades se fundan con ellos, pero tienen otro origen y hasta ahora no se ha podido saber cuál es más antiguo, si el Concejo o la Comunidad. Ni las investigaciones de Martinez Marina

(11) Idem.

(12) SÁnchez Albornoz, España, un enigma histórico, Buenos Aires, 1962.

(13) Villar y Romero, "La Comunidad de Villa y Tierra de Santa María de Albarracín», Estudios homenaje..., cit., pág. 223.

(14) B. Velasco, Historia de Cuéllar, Diputación provincial de Segovia, 1974, página 83. 
y otros poco nuevo han descubierto. Recoge una cita de Pidal, que dice: «En Castilla había varias clases de gobierno, especie de república, que se gobernaban por sí, levantaban tropas, imponian pechos y administraban justicia. Uno de esos gobiernos era el de las Comunidades o Concejon (15).

LECCEA califica de discretos a los que utilizan indistintamente las expresiones Comunidad y Concejo, y dice que si en principio fue igual, el tiempo estableció diferencia. El Concejo es la Corporación que se encarga de la administración de un solo pueblo. Comunidad lo es cuando varios se unen en una sola Corporación.

El disfrute o aprovechamiento común de ganado es el lazo que los une. La guerra les dio origen y por ella adquieren los bienes, la ley las reconoció una vez formadas al igual que a los Concejos de los que son emanación directa. La paz les permitió disfrutar de sus adquisiciones.

- Alejandro Nieto: Conexiona su origen con el de la titularidad de los bienes comunales. Esta recae en el común de los vecinos en cuanto grupo social. Con el correr de los años se forma una Entidad corporativa con personalidad distinta de los vecinos. Hay casos en que no sustituye al común de vecinos en toda su amplitud. Serán supuestos de disociación, uno de ellos lo constituye las Comunidades de Tierra, en las que en la titularidad de los bienes el común de vecinos no es sucedido por un Municipio, sino por varios (16).

El planteamiento - dice- elimina la espinosa cuestión del origen de las Comunidades. El secreto no está en su origen, igual al de los demás Municipios, sino en su desarrollo.

La fundación de Segovia en nada difiere de las demás localidades coetáneas. La Comunidad surge porque con el tiempo nacen decenas de Municipios con personalidad propia, y como ninguno de ellos es lo suficientemente fuerte para apoderarse de los bienes, éstos se confían a la Comunidad. El elemento esencial es el patrimonio, mientras subsistan pervivirán las Comunidades, lo mismo en la época feudal que en la actualidad.

Supone quizá una visión excesivamente patrimonialista de las Comunidades.

(15) Carlos de Leccen, La Cominidad y Tierra de Segovia, capítulo VI, edición de 1894.

(16) A. Nieto, Los bienes comunales, Madrid, Editorial Revista de Derecho Privado, 1964, págs. 318 y sigs. 
En conclusión: 1) Carretero Nieva, Costa, Jiménez y Soler, entre otros, se inclinan por el origen celtibérico de las Comunidades. 2) SÁnchez Albornoz afirma que no cabe esta teoría, su origen es el del Municipio entre el Duero y el Tajo, con precedente en el pequeño Municipio del Duero arriba (17). 3) Hay que partir, en primer lugar, de que el Régimen local es esencialmente pluriforme y diverso en la Edad Media. Concretándose a las Comunidades castellanas de esta Extremadura, podemos afirmar que su origen es el del Municipio entre el Duero y el Tajo. En el siglo XI consta la existencia de la Comunidad de Sepúlveda (18), conocemos una delimitación de términos de esa fecha (19). En el propio siglo tenemos noticias de Cuéllar y su alfoz, y la delimitación de Sepúlveda hace referencia a Cuéllar.

Es necesario distinguir un doble aspecto: a) Político: la repoblación entre el Duero y el Tajo hacen nacer los grandes Concejos, instrumentos de la repoblación. Los Reyes los utilizan para luchar contra la aristocracia señorial y laical. Con Fernando III llegan a su máxima autonomía al amparo de los privilegios que reciben. $b$ ) Administrativo: incrementan su territorio y sus bienes por derecho de conquista o por donaciones. El aprovechamiento de estos bienes es el nexo de unión entre Villa y Tierra, es un medio para cumplir los fines de la Comunidad.

Los bienes se dan a la Comunidad, que conforme repuebla amplía el derecho de aprovechar y asigna bienes a los Concejos. Posteriormente, el patrimonio será su única razón de existir. A medida que crece su importancia política y administrativa se incrementa su influencia patrimonial.

En resumen, son un producto de la repoblación del Duero y el Tajo; fruto de la segunda repoblación concejil, la Comunidad es una forma singular de Municipio. Antes de la repoblación del Duero nace el pequeño Municipio.

(17) SÁNCHez Albornoz, España, un enigma histórico, Buenós Aires, 1962.

(18) El Reglamento de la Comunidad de Villa y Tierra de Sepúlveda (año 1926) afirma que «su fundación se pierde en la antigüedad, suponiéndose fundadamente que es anterior a la confirmación de su fuero a la Villa por el Rey don Alfonso VI en el año 1076 de la Era Hispánica».

(19) Atilano J. Ruiz ZoRrilla y otros autores, Los Fueros de Sepúlveda (los Términos antiguos de Sepúlveda), Diputación provincial de Segovia, pág. 875. 


\section{ORIGEN DE LA COMUNIDAD DE CUELLAR}

No escapa a las reglas generales establecidas. Como Comunidad de la Extremadura castellana le afectan todos los problemas de la repoblación. Surge en la segunda repoblación como Comunidad de Villa y Tierra. Plena de fuerza y pujanza llega al reinado de Alfonso $\mathrm{X}$ el Sabio.

La repoblación de Cuéllar debió seguir a la batalla de Simancas. No parece posible precisar quién la repobló. El Conde Fernán González repobló territorios al sur del Duero y otorgó fueros a Peñafiel. Estos territorios o quizá parte de ellos fueron asignados al Conde de Monzón. PÉREz DE URBel afirma como probable que fue repoblada por el Conde de Monzón (20).

A raíz de la conquista de Toledo, en 1085, avanza hacia el sur la frontera de los cristianos, repoblándose numerosas villas: una de ellas es Cuéllar junto con Iscar, Coca y Olmedo. SÁNCHEZ ALBORNOz expresa que a raíz de la conquista de Toledo surgen una serie de grandes Concejos, entre ellos el de Cuéllar, que tienen un centro urbano y un alfoz o tierra.

EL TUdOLENSE (escribe entre 1197 y 1204) atribuye la repoblación de Cuéllar a Alfonso VI (21). En la Crónica general de España, publicada por MENÉNDEZ PIDAL, aparece Cuéllar como villa repoblada por Alfonso VI.

Es, pues, Cuéllar una de esas Comunidades o grandes Concejos que surgen entre el Duero y el Tajo, con fuertes ciudadelas y núcleos amurallados, con aldeas y con robustas iglesias y castillos, repoblada, en opinión del doctor B. Velasco, por el Conde Pedro Ansúrez casi con toda certeza. El Conde Ansúrez y la Condesa doña Elio, en testamento otorgado el 21 de mayo de 1095, legan diversos beneficios, entre los que figuran varios en Cuéllar y su tierra. El propio Conde anejó al monasterio de Santa María del Remolino el de Sanboal (22).

(20) J. Pérez De URBel, El Condado de Castilla, tomo II, pág. 126. La cita la recoge B. Velasco, Historia de Cuéllar, pág. 79. Lo que sí parece cierto es que Cuéllar fue la zona de fricción de los Ansúrez (reino de León) y el Conde Fernán González. En el año 957 formaba parte del Condado de Castilla, en el 962 debí pasar al Condado de Monzón y en el 985 pasan sus tierras definitivamente al Condado de Castilla (B. Velasco, Historia de Cuéllar, pág. 78, nota :20).

(21) B. Velasco, Historia de Cuéllar, Diputación provincial de Segovia, 1974, página 82.

(22) UbIETo ARTETA, Colección diplomática de Cuéllar, documento 3, Diputación provincial de Segovia, 1961, pág. 15. 
Su tierra o área de influencia, quizá reducida en principio, se va incrementando de un lado por donaciones o ventas reales (en 1184 Alfonso VIII de Castilla vende al Concejo Pedrosillo y sus aldeas, a saber: Fuentealbilla, Adrados y Olombrada, con todos sus términos, prados, pastos, puentes y montes, dándolo al Concejo de Cuéllar «iure hereditario perpetuo») (23), bien por consecuencia de la labor repobladora, cooperando de este modo a la repoblación del país. La toponimia argumenta lo dicho.

En el siglo XI Alfonso VI confirma a Sepúlveda sus términos y en ellos aparece la delimitación con la Tierra de Cuéllar (24), reproducida en mapa que contiene el libro titulado Los Fueros de Sepúlveda, editado por la Diputación provincial de Segovia, y más tarde, a principios del siglo XIII, se hace una delimitación con Aguilafuente. Entre este período debió quedar configurado el alfoz de la Villa y Tierra.

En contra de la opinión de que las Comunidades como estado especial datan de 1088 en León y principios del siglo xIII en Castilla, hemos de decir que la de Sepúlveda existía ya en el siglo XI (25) y que, respecto de la de Cuéllar, la venta en 1184 de Pedrosillo y sus aldeas a aquélla y el testamento del Conde Ansúrez en 1095 no parecen avalar esa tesis de PUSKouski. El primer documento que conocemos del Concejo data del 21 de marzo de 1147, y unos años más tarde, en 1187, el Concejo de Cuéllar estuvo presente en San Esteban de Gormaz (26).

Interesa destacar que Cuéllar nace de la repoblación, que su alfoz se delimita como consecuencia de adquisiciones y de su actividad repobladora, que su nacimiento con área más reducida puede fijarse en el siglo XI, que constituye línea fronteriza entre los Condes de Castilla, que llegan hasta Sepúlveda, y el área de influencia de los Ansúrez, que su apogeo se produce en los reinados de Fernando III y Alfonso X, sin perjuicio de que desde el 985 pase definitivamente al Condado de Castilla.

(23) Idem.

(24) A. Ruiz ZorRilla y otros autores, Los Fueros de Sepúlveda (Términos antiguos), Diputación provincial de Segovia, pág. 876.

(25) B. Velasco, Historia de Cuéllar, Diputación provincial de Segovia, 1974, página 85 , nota 49.

(26) SÁNCHez Albornoz, España, un enigma histórico, tomo II, pág. 81. 


\section{MUNICIPIO Y COMUNIDAD}

El Régimen local en la Edad Media no es uniforme, sino diverso, la mayor o menor autonomía originará Comunidades municipales diversificadas, ya por el carácter y número de sus órganos y oficiales, ya por la amplitud de las atribuciones de la Comunidad o bien por el mayor o menor grado de subordinación al señor o al Rey.

A partir del siglo XII en Castilla el Municipio -dice GaRcia DE Valdeavellano- era ya una entidad de Derecho público, con jurisdicción y autonomía constituida por el Concejo y regida y administrada por sus propios magistrados y oficiales.

En los siglos XIII-XIV los Municipios urbanos con jurisdicción y autoridad sobre las aldeas llegan a constituir un señorío en que el coto era el término y el señor el Municipio.

Todo ello es el fruto de tres etapas o fases:

a) Siglo XI: Municipio rudimentario, primera fase de organización embrionaria que adoptan formas diversas por la mayor o menor amplitud de los privilegios que reciben, por el grado de intervención del Rey o señor en el gobierno, por el número o extensión de sus atribuciones y, finalmente, por el número de oficiales.

b) Siglo xII: Municipio caracterizado por su autonomía jurisdiccional y política y la designación de sus magistrados y oficiales. A su creación contribuyen la concurrencia a un mercado, la defensa en común de una fortaleza y los vínculos religiosos, así como la influencia de los mercaderes en la formación de una conciencia común.

c) Siglo XIII: Se desarrollan los grandes Municipios urbanos, germinados algunos en el siglo XI y asentados en el XII, en el que conquistan su área de influencia. Su jurisdicción y autoridad se extiende a un vasto término municipal.

Hay así dos tipos de Municipios: a) los que ejercen una autoridad sobre un extenso término poblado de aldeas sometidas al gobierno de la ciudad o villa: las Comunidades; $b$ ) los Municipios rurales con jurisdicción y competencia territorial delimitada.

En el siglo XII las ciudades y villas fronterizas entre el Duero y el Tajo someten a su autoridad una amplia demarcación y cons- 
tituyen una Comunidad. Estas Comunidades serán en Castilla las "Comunidades de Villa y Tierra", integradas por la cabecera de la Comunidad (Villa) y las aldeas situadas en el término (Tierra).

\section{CONCEPTO}

- LeCCEA, a los autores que utilizan indiferenciadamente los nombres de Concejo y Comunidad, los califica de discretos, estimando que, si en principio eran conceptos similares, el tiempo los diferencia. Utiliza el término Concejo para la Corporación que representa y administra un solo pueblo, y el de Comunidad, cuando el Concejo representa, gobierna y administra varias poblaciones encuadradas dentro de una misma comarca (27). Quizá la expresión Concejo deba ser considerada como genérica y referida al órgano que gobierna y representa a la Entidad municipal, cualquiera que sea la forma que adopte (Municipio o Comunidad).

Esta forma singular del Municipio se nos presenta con diversos nombres: Comunidades de Ciudad y Tierra, o de Villa y Tierra, y Universidades de la Tierra. Encontramos también las denominaciones de "Asocio de la Universidad y Tierra», referida a Avila; Comunidad de Tierra, etc.

En ningún aspecto (territorial, personal y de autonomía) constituyen las Comunidades un todo compacto, sino más bien una agregación de Entidades locales ordenadas en una estructura orgánica y jerárquica (28). La agrupación de pueblos en torno a una ciudad o villa que ejerce un papel directivo hacia el interior y que los representa en el exterior, eso es la Comunidad.

- Riva y García expresa que en el siglo XII se llama Comunidad al régimen particular de un territorio del que es cabeza una villa de realengo o independiente que, por concesión del monarca, forma un pequeño estado con fuero propio y mancomunidad de intereses y obligaciones (29).

El territorio le era dado al Concejo, a la ciudad o a la villa en igual forma que a un Obispo o a un Abad. Los pobladores de

(27) Carlos de Leccea, La Comunidad y Tierra de Segovia, capítulo VI.

(28) Rafael Giberr, El Concejo de Madrid, Madrid, Instituto de Estudios de Administración Local, 1949, capítulo VIII, pág. 73.

(29) Villar Y Romero, "La Comunidad de Villa y Tierra de Santa María de Albarricinn, Estudios homenaje..., pág. 223. 
las aldeas dependian del Concejo de la villa o ciudad cabecera de la comarca, eran generalmente de condición pechera y estaban obligados al pago de los repartimientos.

- Carretero Nieva expresa que las Comunidades constituyen un islote jurídico autónomo dentro de la administración territorial. Eran como un pequeño estado con su fuero propio y mancomunidad de obligaciones en materia de pastos y represión de delitos y cuyos componentes son un substrato geográfico y humano vascoceltibérico, el elemento germánico popular y el factor demográfi. co y sociológico de la repoblación (30).

- García de Valdeavellano nos da quizá uno de los concep. tos más precisos. El Concejo de la ciudad o villa abarcaba bajo su autoridad una amplia demarcación o territorio (el alfoz o tierra) y formaba una comunidad de población que era su centro, zona en la que había otras localidades en las cuales el Concejo procedía a establecer poblaciones cooperando a la repoblación. Estaban unidas por el régimen común de la ciudad o villa, cabecera de la Comunidad. Tales Comunidades deben su origen a la repoblación de los grandes Concejos, a los que se asigna un vasto término para repoblar mediante el asentamiento de poblaciones que se organizan en Concejos rurales sometidos a la jurisdicción del Concejo general de la villa o ciudad. Necesidades económicas agrarias (aprovechamientos en común) hicieron cada vez más fuertes los víncu. los entre los Concejos rurales y el Concejo de la ciudad o villa de que dependían (31).

El régimen de Villa y Tierra -afirma Gibert (32) - está muy extendido en el territorio castellano-leonés. Su estudio debería comenzar con el diseño de un mapa expresivo de la base territorial de estas Comunidades.

Las Comunidades constituyen un fenómeno peculiar, aunque no exclusivo de Castilla. Las Comunidades propiamente dichas se localizan en la Extremadura castellano-aragonesa. A partir del siglo $\mathrm{x}$, cuando Castilla pasa el Duero a raíz de la batalla de Simancas, van surgiendo las Comunidades castellano-aragonesas. En Castilla, las de Avila, Segovia, Soria, Guadalajara y Cuenca, a las que V. DE LA FUENTE considera como organizaciones de esta clase más im-

(30) CaRretero Niria, Las Comunidades castellanas en la historia de Segovia, 1929 , pág. 26.

(31) García de Valdeavellano, Historia de las Instituciones, 1968, págs. 542 y siguientes.

(32) Rafael Gibert, El Concejo de Madrid, capítulo VIII, pág. 75. 
portantes (33), y las de Arévalo, Portillo, Peñafiel, Iscar, Coca, Fuentidueña, Sepúlveda, Maderuelo, Montejo, Fresno de Cantespino, Cuéllar, Haro, Roa, Ayllón, Almazán, Atienza, Molina de Aragón, Daroca, Calatayud, Teruel, Albarracín, Mosqueruela y Madrid. En el reino leonés (Extremadura leonesa), y al oeste del Pisuerga, sólo se constituye la de Salamanca (34), extensa e importante, con características semejantes a las aragonesas.

Las Comunidades de Calatayud, Daroca, Teruel y Albarracín eran como pequeñas repúblicas sujetas a un mismo soberano, si bier en lo económico y lo político se regían por sus ordenanzas particulares (35).

Posteriores a la Reconquista surgen algunas Comunidades: la de Cáceres y sus pueblos (año 1479), la de la Sierra de Santiago de Lozquiz (Navarra, año 1357), la del Valle del Roncal, el Asocio de la Universidad y Tierra de Avila, Campóo, Cabuérniga, la Comunidad de las Bárdenas Reales, Maderuelo y Pedraza y su Tierra (36).

Todas las enunciadas no constituyen una enumeración exhaustiva. Nieto cita en su obra, Los bienes comunales, muchas más en las Provincias de Albacete, Almería, Avila, Badajoz, Soria, Teruel, Valladolid y Vizcaya, recogiendo experiencias profesionales de RoDRf́GUEz MORo. Aunque todas ellas sean la expresión de fórmulas asociativas municipales, no creemos obedezcan en su origen al concepto de Comunidad como forma singular del Municipio medieval.

Dentro de las grandes Comunidades castellanas no es Cuéllar, ni mucho menos, la más importante, ni siquiera de las más importantes, pero sí obedece al concepto más puro de las Comunidades de Villa y Tierra. Nace en la primera época en una zona en que esta fórmula organizativa tuvo su más amplia y pura manifestación. Sus fronteras están delimitadas casi exclusivamente por Comunidades de Villa y Tierra (Segovia, Fuentidueña, Sepúlveda, Penafiel, Portillo, Iscar y Coca), salvo por el Concejo de Aguilafuente. Tuvo un importante peso específico en la historia de Castilla. Quizá no muy celosa de su autonomía, que sacrifica en beneficio de su existencia y pujanza.

(33) González Herriro, Segovilu, pucblo, ciudad y ticrra, Segovia, 1971, pág. 58.

(34) Idem.

(35) Ignacio b: Asso, Historia de la economia política de Aragón, capítulo I, página 23.

(36) Villar y Romero, “La Comunidad de Villa y Tierra de Santa María de Albarracín», Estudios homenaje..., pág. 223. 


\section{CARActeres}

El Régimen local en la Edad Media es diverso, la mayor o menor autonomía origina comunidades diversas. La Administración local de los siglos XIII-XVII todavía sigue siendo más importante que la territorial y es continuación de la nacida en el siglo Xr. Los órganos de este Régimen aparecen en general con las denominaciones de ciudad o villa. La calificación de cada núcleo en uno u otro sentido es un fenómeno histórico en el que no intervienen factores eclesiásticos, militares, etc. Cuéllar es villa, y en su alfoz encontramos asentamientos de población con las denominaciones de aldeas, arrabales, castillo y torre.

La cooperación entre la villa y las aldeas es manifiesta y cons. tante. Hay unos intereses y fines comunes y otros de cada Concejo. A los primeros tiene que cooperar la villa y las aldeas (muros, castillos, caminos, etc.).

Hay una distinción entre casco urbano y alfoz, con repercusiones importantes en el aspecto fiscal y en la vida económica. En el alfoz hay agrupaciones pequeñas de población, pero que -como dice PÉREz PRENDES - no tienen ordenación propia, dependen de la ciudad o villa y no son entidades administrativas; son los arrasbales (37).

- Esteban ABAD, en su estudio sobre la ciudad y Comunidad de Daroca, recoge una serie de caracteres o notas atribuibles al régimen de la Comunidad, a las que el paso del tiempo imprimirá su impronta. Son:

Libertad e ingenuidad de sus habitantes. Todos los fueros y privilegios que reciben de la Corona tienen como meta la mayor autonomía y libertad del Concejo y sus habitantes.

Sumisión directa al Rey con exclusión de señorío feudal. Los Municipios con jurisdicción y autoridad sobre las aldeas llegan a. constituir un señorío. La Comunidad de Cuéllar, desde el siglo XII hasta mediados del siglo $\mathrm{xv}$, es independiente o depende de miembros de la familia real (38).

A partir de Juan II se consolida en la Villa y Tierra el régimen señorial.

(37) Pérez Prendes, Apuntes de historia del Derecho (carncteres de la Administración local en los siglos XIII-XVIII), Madrid, 1964.

(38) Ubieto ARTeta, Colección diplomática de Cuéllar. Introducción, XIX, Diputación provincial de Segovia, 1961. 
Fraternidad e igualdad entre las aldeas. Todas ellas gozan, respecto de la villa, de una consideración semejante. Tienen una personalidad propia legal inferior, una misma organización, unos mismos derechos y unas mismas obligaciones. Ocasionalmente encontramos en Cuéllar cierta posibilidad privilegiada en las aldeas, concretamente en las de Sanboal y Nava de Oro y en alguna que otra también limítrofe o colindante con la raya (39), llegándose a equiparar a efectos de pechos sus habitantes a los caballeros de la villa, si bien han de soportar ciertas prohibiciones más rigurosas derivadas quizá de los vecinos de Dehesa y Dehesa Mayor en el aprovechamiento de pastos, participando de los beneficios de la dehesa boyal (Prado Vega) de la villa de Cuéllar (40).

Mancomunidad de intereses e igualdad y unidad de fuero. Existen unos fines e intereses comunes a los que deben contribuir. Los aprovechamientos de montes, prados, etc., comunes, sirven de nexo de unión y son la expresión de esta comunidad de intereses. El Fuero Real que Alfonso $X$ otorga a la villa se da para que rija en la Villa y Tierra. Las Ordenanzas que sucesivamente se aprueban tienen un ámbito territorial de vigencia que comprende Villa y Tierra.

Propia y exclusiva organización, tanto económica como administrativa y judicialmente, constituyen una auténtica Provincia exenta y unida a la Corona, celosa de sus libertades.

Unidad económica. La villa es el centro de una zona o comarca artesana, industrial y ganadera.

- Riva y García recalca como notas esenciales de toda Comunidad: $a$ ) ser villa realenga e independiente de todo señorio; $b$ ) tener señorío territorial exento con dominio sobre las aldeas del territorio que debían seguir su pendón; $c$ ) tener fuero único con jurisdicción civil y criminal, y $d$ ) tener mancomunidad de pastos y otros derechos con las aldeas (41).

En la Baja Edad Media surge un auténtico feudalismo concejil. Las Comunidades tienen los derechos atribuidos a los señores, Obispos y Abades, no sólo en la villa, sino sobre las aldeas. Los autores - dice NIETo- se han dejado sugestionar en exceso por esta organización feudal que adoptan las Comunidades a partir del siglo XIII.

(39) De la TORre y Trasierra, Cuéllar, Madrid, 1897, segunda parte, apéndice documental XXVI.

(40) Ordenanzas de la Villa de Cuéllar de 1546. Ley 94.

(41) Alejandro Nieto, Los bienes comunales, Madrid, 1964, pág. 321. 


\section{Caracteres de la de Cuéllar}

Las Comunidades en su origen son la máxima expresión de la autonomía y poderío municipal (feudalismo municipal). La Comunidad de Cuéllar se caracteriza: 1) Tiene su origen en la repoblación, es instrumento de ella y de hecho es utilizada en principio contra el poder de los señoríos laicos y eclesiásticos. 2) Nos manifiesta la existencia de una Comunidad de población y territorio sin perjuicio de una vecindad específica y territorio propio de cada Concejo. 3) Está unida bajo un régimen común que comprende la villa y los poblados sometidos a la autoridad de la primera, sin perjuicio de la limitada autonomía de los Concejos, que en algún modo participan en el régimen de la Comunidad. 4) Unidad de fueros y ordenanzas, unidad de jurisdicción y unidad económica. 5) El Concejo extiende su autoridad a una amplia demarcación con sumisión de los Concejos rurales a la jurisdicción superior de la villa. 6) El vínculo que mantiene esa conciencia de Comunidad es esencialmente económico (las necesidades económicas, agrarias, aprovechamiento de pastos, etc.).

\section{Naturaleza y Personalidad}

Hasta el siglo XI los centros de población fueron agrupaciones humanas no tomadas en cuenta por el Derecho. En este siglo nos consta la existencia de aldeas y lugares (42) en la tierra de Cuéllar, lo que no nos consta es la incorporación formal de las aldeas, el sentimiento de los pueblos al Concejo. En definitiva, que existiera la organización jurídico-pública de la Villa y Tierra.

En el siglo XII en Castilla el Municipio es ya una Entidad de Derecho público. Tiene una personalidad jurídico-pública. Paralelamente, el Municipio singular que surge entre el Duero y el Tajo adquiere, mediante las vinculaciones e incorporación de las aldeas a las que somete, el carácter de Entidad de Derecho público.

En carta de Alfonso VIII, que firma en Belvis, el Concejo de Cuéllar adquiere Pedrosillo y sus aldeas, que incorpora a su Concejo. Cabe ya afirmar la existencia de una organización jurídico-

(42) B. Velasco, Historia de Cuéllar, Diputación provincial de Segovia, 1974, página 83. 
pública (43) de un Concejo con jurisdicción sobre sus aldeas sometidas en alguna medida a la villa.

La personalidad de la Villa y Tierra surge desde el momento en que constituyen un todo orgánico y jerárquicamente dispuesto. El conjunto posee personalidad jurídica fundada en una serie de circunstancias y problemas comunes; no obstante, cada aldea tiene su propia personalidad subordinada y de segundo grado con su propia organización y su propio Concejo, tanto más definido cuanto avanzamos en el tiempo.

El Concejo de Cuéllar es un Municipio libre, vinculado a la Corona desde el siglo XII hasta mediado el siglo XV. El mantener su integridad e independencia es una constante exigencia en él, así como la preocupación por confirmar sus fueros y privilegios (44). Ello no quiere decir que estas mismas tendencias no se den en los Municipios y Comunidades castellanas.

Hacia el exterior no existe más personalidad que la de la Comunidad. Ante el Rey o ante las Cortes, quien únicamente tiene representación, en su caso, es el Concejo de la villa. La Comunidad, como tal, tiene fuerza y gracias a ella las aldeas y la villa se bastan a sí mismas y no precisan protección, sirviendo a la Corona para contrapesar el poder de la aristocracia.

Ningún señorío, por su población, fuerza militar y poder económico (pensemos, por ejemplo, en el reinado de Alfonso X), podría compararse. Constituye un auténtico estado con poder político. La villa gobierna todo el territorio, representa a la Comunidad hacia el exterior y subordina a las aldeas.

La personalidad de la Comunidad de Tierra adquiere así una doble proyección política y jurídico-administrativa. Es una entidad intermedia entre la Corona y las aldeas, de carácter territorial, que asume una pluralidad de fines y competencia y que tiene un carácter corporativo. Las aldeas, en muchos casos, no se han incorporado espontáneamente y por su libre voluntad.

Después de lo expuesto podemos afirmar que la Comunidad de Villa y Tierra es una forma singular de Municipio que surge en la Edad Media, en la zona que enmarca el Duero y el Tajo, a consecuencia de la Reconquista y como instrumento de ella, que actúa

(43) Ubieto ARteta, Colección diplomática de Cuéllar, documento 3, Diputación provincial de Segovia, 1961, pág. 15.

(44) UBIETo ARTETA, Colección diplomática de Cuéllar. Recoge infinidad de documentos en los que los Reyes confirman Fueros y Privilegios. 
al servicio de la Corona como freno de la aristocracia señorial y eclesial.

Sus caracteres no son siempre coincidentes por la disparidad y diversidad de fueros y privilegios. Comprende un núcleo o cabecera con un área de influencia sembrada de aldeas, unas integradas y otras repobladas, fruto de su acción colonizadora.

Está dotada de personalidad jurídica y autonomía política y administrativa, con su propia jurisdicción y organización administrativa, judicial, militar y comunidad de fuero. Constituyen una agre. gáción no homogénea y un todo orgánico jerárquicamente ordenado. Su patrimonio es un nexo de unión e instrumento para el cumplimiento de sus fines.

El transcurso del tiempo va modificando sustancialmente este concepto y característica.

\section{ESTRUCTURA: VILLA Y ALDEAS. VINCULO Y SEXMOS.}

Cada villa o ciudad tiene un amplio territorio, una zona rural extensa que forma con ella una unidad política, social y económica. Una declaración expresa de sujeción de las aldeas a la villa va implícita en la concesión de términos.

El término que se delimita de Segovia - dice GIBERT- se concede al Concejo de Madrid, que tendrá plenam potestatem vetandi et defendendi eos $a b$ aliis conciliis qui contra volurtatem vestram... voluerit in eis sibi damnum vindicare (45). Los títulos de pertenencia de las aldeas a la villa serán: la repoblación por el Concejo, la compra o la donación.

Conveniencias económicas de aprovechamientos comunes de pastos y bienen lo mantienen. El tiempo y los abusos en muchos casos irán debilitando el vínculo, y ya en el siglo XVI algunas poblaciones se segregan al concedérsele por los Reyes el derecho de villazgo. La villa y las aldeas de Cuéllar, con algún supuesto excepcional, nacido de arriba, permanecen vinculadas hasta la fecha.

La estructura es muy simple: la villa y la tierra. Dentro de la villa amurallada y con sus puertas de acceso, la ciudadela, y en su centro, el castillo. Distinción con repercusiones interesantes es la clasificación de habitantes en "intramuros y extramuros», según

(45) Rafael Gibert, El Concejo de Madrid, Madrid, Instituto de Estudios de Administración Local, 1949, capítulo VIII, pág. 75. 
vivan dentro de las murallas de la ciudad o villa o fuera de ella. Los arrabales alejados de la villa son poblados que no adquieren la condición de aldeas y son los todavía subsistentes de Escarabajosa y Torregutiérrez (46).

La Tierra, alfoz o área de influencia y límite de la jurisdicción en la que las aldeas se hallan encuadradas.

La villa se halla dividida en colaciones, es un conjunto de colaciones o parroquias. En Cuéllar sólo encontramos referencia a la colación de San Esteban y a la de San Miguel. La Tierra está estructurada en sexmos que agrupan un determinado número de aldeas.

El sexmo es una circunscripción o distrito territorial. La villa en ocasiones llegará a constituir un sexmo por sí sola. La denominación de esta circunscripción, como hemos visto, no es constante ni uniforme; en unos casos se llamarán ochavos; en otros, cuartos; en otros, sexmos, y en algún caso, como en la Comunidad de Coca, no aparece esta división.

El sexmo supone un elemento estabilizador. Los sexmos son invariables y con frecuencia iguales. En torno a ellos suelen girar los derechos y obligaciones. Su influencia es doble, de un lado afecta a los aprovechamientos y a la participación en los beneficios, y de otro, a la participación en el gobierno y administración de la Villa y Tierra.

El vínculo entre Villa y Tierra se verá ampliamente debilitado, y la desvinculación se producirá no sólo por la autonomía que supone el derecho de villazgo, que de los Reyes se solicita, sino alzándose la Tierra contra la villa o ciudad y reivindicando su autonomía frente a ella (Comunidad aragonesa de Daroca). Las aldeas, sintiéndose fuertes y unidas, se alzan contra la Comunidad, de la que queda excluida la villa. No es éste el caso de Cuéllar, donde la Tierra y la Villa permanecerán unidas.

\section{EVOLUCION Y DISOLUCION}

A principios del siglo xvi atraviesan las Comunidades una fase de popularidad y expansión, que va a significar su canto de cis-

(46) Ubieto ARTETA, Colección diplomática de Cuéllar. Introducción, XXIV, Diputación provincial de Segovia, 1961. 
ne (47). En esta época existen, o llegan a ella como más importantes en Castilla, las de Segovia, Avila, Cáceres y Cuéllar. Huelga advertir que su concepto y características han sufrido una profunda transformación; su organización político-administrativa quizá se conserva e incluso se potencia, pero la tendencia centralizadora a través de la expansión del Derecho territorial, el nombramiento de funcionarios y oficiales y, sobre todo, el paso al Regimiento anula totalmente su valor y potencia política.

En la guerra de las Comunidades la institución del Corregidor y el Regimiento han arraigado ya; Cuéllar ha dejado, desde mediados del siglo XV, de ser independiente a dependiente de la Corona, ya no es realengo.

En el siglo XIX se interrumpe la pujante vida de las Comunidades mediante la promulgación de una Real Orden, que dispone bruscamente su disolución y la venta de sus patrimonios (48). No es, sin embargo, esta Real Orden la que interrumpe su vida, es el ad. venimiento del régimen constitucional y el liberalismo el que producirá un impacto en su organización político-administrativa, en su estructura. Políticamente ya habían dejado de tener significado.

La Real Orden pretenderá acabar con ellas, y si en muchos casos no lo consigue, sí transformará sustancialmente su naturaleza. Muchas de ellas, debilitadas, arrastrarán una vida lánguida.

Lo mismo que cada individuo vive y actúa en el Estado con independencia, también cada pueblo tiene su personalidad política y administrativa propia. Los principios de libertad e igualdad ante la ley del individuo, se transmiten a la vida municipal, y lo curioso es que toman como fundamento el Derecho medieval, que nos dice justamente lo contrario.

Los Concejos, integrados y subordinados al Concejo de la villa, consiguen su plena autonomía y se equiparan a aquélla. Lo único que ya les unirá es el patrimonio común, que les sirve de nexo o vínculo y de medio para el cumplimiento de unos fines que ahora asumen individualmente en su totalidad y amplitud cada uno de los Concejos rurales. Su personalidad será de igual rango que la de la villa.

Cuando se promulga la Real Orden de 31 de mayo de 1837, el régimen constitucional, con diversas alternativas, lleva más de

(47) José Antonio Maravall, Las Comunidades de Castilla, 1963, pág. 322; cita que recoge Alejandro NIETo en Los bienes comunales.

(48) Alejandro Nieto, Los bienes comunales, Madrid, 1964, pág. 323. 
quince años de vigencia. Ha agotado su período de vigencia la Constitución de Cádiz de 1812 y nace la de 1837. En todos los pueblos debía haber Ayuntamiento.

La Orden se dicta por el Ministro de la Gobernación para resolver un expediente particular referente a la Universidad de la Tierra de San Pedro de Manrique. La Real Orden se fundamenta en la Constitución y en la vigencia de la Ley de Cortes de 3 de febrero de 1823. Su fundamento, en principio, es irreprochable, según se deduce de su exposición de motivos: a) que se formen Ayuntamientos donde deban tenerlos; $b$ ) que son innecesarias y gravosas por cuanto sus atribuciones deben transferirse a los Ayuntamientos, y así manda:

- Que se supriman las Juntas o Ayuntamientos generales de la Universidad de Tierra de San Pedro de Manrique y cualquier otra de otra clase en la Provincia.

- Que se enajenen sus propios.

- Que se informe si hay atribuciones de la Junta que no que. pan dentro de las propias de las Diputaciones y Ayuntamientos.

El fundamental problema que plantea esta Orden es su generalidad, problema que abordan, entre otros autores, ALvarEz-Gendín, Villar y Romero, Leccea y NiETo.

Este último autor se inclina por su generalidad, que deduce del texto literal Sirva de regla general, de que en la práctica se reconoció así y se fueron disolviendo y de que así fue declarado por la jurisprudencia, que en forma abundante cita.

LECCEA hace, sin duda, la más severa crítica de la Orden: "La Orden la dicta un Ministerio sin atribuciones legislativas». Viene a considerarlas como Ayuntamientos irregulares, desconociendo lo que realmente es una Universidad o Comunidad. No hace más referencia que a los propios y no a los comunales.

No obstante su generalidad, aunque injustificable, no admite réplica (49). Sus consecuencias fueron que donde se enajenaron, el Ayuntamiento cabecera se apropió de los bienes. La realidad es que muchas se disolvieron y que otras subsisten porque es difícil que una institución consuetudinaria y milenaria quede desarraigada por una Real Orden (50).

(49) Carlos DE LecceA, La Comunidad y Tierra de Segovia, capítulo VIII.

(50) Alejandro Nieto, Los bienes comunales, Madrid, 1964, pág. 326. 
Lo cierto es que, desmontada la estructura orgánica y funcional de las Comunidades, quedaba un patrimonio, en ocasiones cuantioso, tal es el caso de la de Cuéllar, sin administrador.

La Real Orden considera que deben desaparecer y ordena la primera desamortización, que incide realmente en lo que era la esencia y razón de existir de las Comunidades una vez producida la autonomía de las aldeas.

La Comunidad de Villa y Tierra de Cuéllar ante esta situación reacciona en su defensa y salva su existencia, obteniendo la promulgación por la Regencia de la Orden de 22 de noviembre de 1840, por la que se dota de órgano de administración al patrimonio. Se dispone que los representantes de los sexmos continuarán administrando los bienes. Los Jefes políticos de Valladolid y de Segovia (en la división provincial el término de la Comunidad quedó dividido entre Valladolid y Segovia) instaron la regulación de la forma de administrar. Las Juntas se celebran en Cuéllar. La Comunidad de Segovia más tarde conseguirá un privilegio análogo.

\section{EVolución a tRAvÉS DE LAS LEYES DE REGIMEN LOCAL}

La primera Ley de Régimen local, la de 1845, abre un paréntesis de silencio que dura más de treinta y tres años. No contiene ninguna norma referente a Comunidades ni Mancomunidades.

La Ley de 1870, en sus artículos 68 y 69, permite la asociación de Municipios para el cumplimiento de sus obligaciones, y en el artículo 75 permite formar asociaciones y Comunidades, entre otros fines, para el aprovechamiento de bienes vecinales. Por fin la Ley de 1877 reconoce su existencia y mantiene sus normas tradicionales sobre administración de bienes. Una Real Orden de 1 de julio de 1892 ratifica su subsistencia y permite su reglamentación.

$\mathrm{La}$ realidad se impone, los pueblos se resisten a vender bienes que les son vitales y que siguen administrando por Juntas integradas por los sexmeros.

El Estatuto municipal, en su artículo 10, da un paso importante para comprender su naturaleza jurídica actual al expresar que «las Mancomunidades existentes conservarán su régimen" y las integra detro de las asociaciones de Municipios. La vigente Ley de Régimen local (artículos 31 y40) y los Reglamentos de Población y Demarcación territorial (artículos 69 a 71) (Sección 3." del Capítulo VII) 
y el de Organización, Funcionamiento y Régimen jurídico (artículo 101) les dedica una especial atención.

La legislación local primero las ignora por entenderlas contrarias a la Constitución y más tarde por unirse a este argumento la disolución decretada y el fenómeno de la desamortización. Pasado este periodo en su principal etapa, les abre tímidamente camino a través de las asociaciones y Comunidades para aprovechamientos vecinales. Finalmente, las admite canalizándolas hacia las Mancomunidades de Municipios.

\section{SITUACION ACTUAL}

\section{REPERCUSIÓN DE LAS LEYES DESAMORTIZADORAS}

Independizadas las aldeas y constituidas en Municipios de igual rango que la villa, restan patrimonios sin administrador. En Cuéllar los sexmeros (Junta Liquidadora) asumen la administración y liquidación. Se salva su patrimonio, en principio, por la norma excepcional obtenida y subsiste la Comunidad sin el carácter de Entidad local de Derecho público.

Una nueva causa coopera a su ignorancia en las Leyes de Régimen local, es la desamortización. Se declaran en estado de venta los bienes, propiedades y derechos de las Entidades locales. Las Comunidades se acogen a las excepciones, no obstante la jurisprudencia negarles personalidad jurídica para solicitarlo.

Una situación confusa se va a producir. Las Juntas administradoras carecen de personalidad jurídica para pedir excepciones porque las Comunidades legalmente habían dejado de existir. Estas Juntas, lógicamente, la de Cuéllar por supuesto, se resisten a liquidar y dividir los derechos comunes, así como a adjudicar a cada parte lo que le corresponda de los bienes comunales.

La legislación desamortizadora exceptúa de venta los bienes comunales y los montes de una determinada superficie; LECCEA afirma que su división es imposible.

Por la posibilidad que abre la Ley de 1877, y sobre todo la Real Orden de 1 de julio de 1892, clarifican la situación al ratificar su subsistencia y permitir su reglamentación. Cuéllar ve regularizada su Comunidad al aprobarse, tres años más tarde, su primer Reglamento en sesión de su Junta General de Procuradores de 1895. 
Conclusiones: 1. Desde el advenimiento del régimen constitucional subsisten en sus bienes, en su estructura orgánica y con personalidad jurídica hasta 1837 , en cierto modo al margen de la legalidad.

2." De 1837 hasta la Ley de Régimen local de 1877, las Comuni dades se disolvieron y su patrimonio desapareció, salvo, entre otros casos, en la de Cuéllar, en la que la Real Orden de la Regencia de 22 de julio de 1840 ordena que una Junta de liquidación y administración de los bienes comunales proceda a realizar la división de los derechos comunales. A esta Junta se le niega personalidad jurídica. Subsiste sólo el patrimonio.

3. La Ley municipal de 1877 mantiene el statu quo sobre su administración y la vigencia de las normas consuetudinarias. Entran dentro de la esfera de influencia de las Mancomunidades. Se les reconoce personalidad y consta que en 1886 funciona ya una Junta General de Procuradores en Cuéllar. Una Real Orden de 1 de julio de 1892 ratifica la subsistencia y les permite reglamentarse, lo que hace la Comunidad de Villa y Tierra de Cuéllar al aprobar, en sesión de 8 de noviembre de 1895, su primer Reglamento. Tendrá así personalidad jurídica, pero no el carácter de Entidad local.

La Ley de Régimen local les dedica especial atención y en su normativa viene a reconocerles personalidad jurídico-pública y el carácter de Entidad local.

\section{Personalidad y naturaleza}

A la vista de los antecedentes históricos y legislativos y de la normativa vigente, no parece que pueda ponerse en duda la personalidad de las históricas Comunidades de Tierra, a juicio de VILLAR Y ROMERO (51).

Tienen personalidad jurídica autónoma propia e independiente. Son Entidades supramunicipales sensiblemente análogas a las Mancomunidades. Constituyen Corporaciones de interés público a las que se refiere el artículo 35,1 , del Código civil.

Esta tesis aparece recogida en diversas sentencias del Tribunal Supremo (17 de enero y 19 de abril de 1901, sentencia de la Sala

(51) Villar y Romero, «La Comunidad de Villa y Tierra de Santa María de Albarracín», Estudios homenaje..., pág. 256. 
de lo Contencioso-administrativo del Tribunal de Supremo de 29 de septiembre de 1950). Todas ellas proclaman su personalidad.

La personalidad y naturaleza de la Comunidad de Villa y Tierra de Cuéllar ha sido definida por el Tribunal Supremo al amparo de la actual legislación (52). La Sala de lo Civil deja precisado con rotunda claridad:

- Que a partir de la Ley de 1877 habrá que admitir se trata de una Corporación de interés público, y ello por dos razones: 1) Porque su forma es corporativa, ya que sus miembros acceden a ella por los cargos concejiles que ostentan en los respectivos Ayuntamientos y la presidencia está vinculada a la Alcaldía de Cuéllar. 2) Porque existe un sensible paralelismo con las Mancomunidades y agrupaciones desde la Ley de 1877, hasta el punto de que podrán ser sometidas a lo dispuesto sobre agrupaciones forzosas intermunicipales.

- Que en ningún modo puede ser considerada como asociación con fines privados.

En definitiva, la Comunidad de Villa y Tierra antigua de Cuéllar es una Entidad pública de carácter corporativo e interés público, supramunicipal y de régimen muy similar al de las Comunidades con personalidad autónoma distinta de la de los Municipios que la integran.

\section{MANCOMUNIDADES Y COMUNIDADES}

La Ley de Régimen local en 1870 abre un nuevo camino a las Comunidades que consolidan la de 1877 y el Estatuto municipad. La Ley de 1935 las dedica un precepto fundamental, el artículo 29: «Se respetarán las antiguas Comunidades de Villa y Tierra; si se produjeren reclamaciones sobre su administración... podrá someterse a lo dispuesto en este Capítulo" (el artículo está encuadrado dentro de la Sección 3. ${ }^{\text {, }}$, Capítulo I, Agrupaciones intermunicipales).

La Ley de Régimen local vigente, en su artículo 40, dice: «Se respetan integramente las antiguas Comunidades de Tierra..., pudiendo ordenarse se constituyan en agrupaciones forzosas». Las Comunidades comienzan a penetrar a través de las Mancomunidades y agrupaciones como manifestación del derecho de asociación mu-

(52) Sentencia del Tribunal Supremo (Sala de lo Civil) de 10 de abril de 1954. 
nicipal, único camino posible, ya que, al elevarse al rango de $\mathrm{Mu}$ nicipios, las Comunidades dejan de ser una agregación orgánica y jerarquizada, y la única forma de existencia de esta unión es el derecho de asociación entre iguales.

Hoy -afirma NiETo- no son más que variedades del género Mancomunidad-agrupaciones (53) porque su objeto entra dentro de los fines de la competencia municipal, y se regulan dentro de una misma sección («De las Mancomunidades y agrupaciones») porque pueden pertenecer a distinta Provincia. Se rigen por sus Estatutos (artículos 31 y 38 de la Ley de Régimen local y 70 del Reglamento de Población) y tienen capacidad para el cumplimiento de sus fines (artículos 32 y 38 de la Ley de Régimen local).

Existen, no obstante, diferencias; las resoluciones de Mancomunidades y agrupaciones agotan la vía administrativa. En las Comunidades cabe recurso ante el Ministro de la Gobernación.

El régimen de aprobación de los Estatutos es distinto (los de las Comunidades basta con ponerlos en conocimiento del Ministro de la Gobernación), así como su contenido, ya que en las Comunidades prevalece lo tradicional, mientras que en las Mancomunidades han de ajustarse en todo a la legislación local en vigor.

El régimen económico es semejante, sin perjuicio de su autonomía. El orden de prelación de fuentes aplicables es: 1) el régimen tradicional; 2) sus Estatutos, y 3) el Régimen local. El elemento tradicional no tiene, por el contrario, ningún valor en las Mancomunidades y agrupaciones.

Sienta Nieto dos conclusiones: $1 .^{a}$ Que en el futuro no pueden constituirse; y $2 .^{a}$ Que los mismos objetivos que cubren las Comunidades puedan hoy conseguirse con una Mancomunidad.

La legislación local respeta, en principio, su autonomía y régimen tradicional, principio que inculcan los preceptos reglamentarios al ir en su intervencionismo más allá de lo querido por la Ley de Régimen local, en su artículo 40 (54), en materia económica. Aparte de ello, la pérdida de la autonomía y, en definitiva, su no tardía transformación en Mancomunidades se produce por la fuerza atractiva que la legislación local ha ejercido en la redacción de sus Estatutos, a los que se incorporan sus preceptos, en ocasiones literalmente, por el creciente intervencionismo de la Administración no sólo en su desarrollo económico, sino en todos sus aspectos

(53) Alejandro Nieto, Los bienes comunales, Madrid, 1964, pág. 341.

(54) Alejandro Nifto, Los bienes comunales, Madrid, 1964, pág. 342. 
(personal, contratación, etc.), por la tendencia de sus rectores y funcionarios a aplicar en todas sus facetas la normativa local, cuando sólo lo realmente vinculante es la intervención económica. La Comunidad de Cuéllar no escapa a esta corriente general. De sus normas tradicionales no resta más que su estructura orgánica y asignación de competencias.

Como conclusión de todo el capítulo y precisamente para captar realmente lo que son las Comunidades, la Comunidad de Cuéllar y su proceso de transformación, hemos de distinguir cuatro etapas perfectamente diferenciadas en él:

1. ${ }^{2}$ Original. De plena autonomía política y administrativa, en la que incluso son titulares de poder político. Esta concepción ha ejercido notable influencia y ha deformado y politizado, por el tiempo, su concepto.

2. ${ }^{a} \quad$ En ella la influencia del Derecho territorial y la política centralizadora, que se inicia con la instauración del Regimiento y el nombramiento de Corregidores, la convierten en Entidad municipal singular dotada de autonomía que con el tiempo va perdiendo progresivamente hasta llegar al régimen constitucional.

3. En ella desaparecen como Entidades locales y como personas jurídicas. Algunas sólo salvan su patrimonio al amparo de las Ordenes citadas, que permiten la constitución de Juntas administrativas. Esta etapa concluye en 1870.

4. ${ }^{\mathrm{a}}$ Que comprende el proceso de transformación en Entes n̄o territoriales, sino institucionales, en Mancomunidades dotadas de ciertas particularidades, que terminarán por desaparecer. 
REVL-1977, núm. 193. CORRAL GARCIA, ESTEBAN. LAS COMUNIDADES Y LA COMUNIDAD DE V... REVL-1977, núm. 193. CORRAL GARCIA, ESTEBAN. LAS COMUNIDADES Y LA COMUNIDAD DE V... 
REVL-1977, núm. 193. CORRAL GARCIA, ESTEBAN. LAS COMUNIDADES Y LA COMUNIDAD DE V...

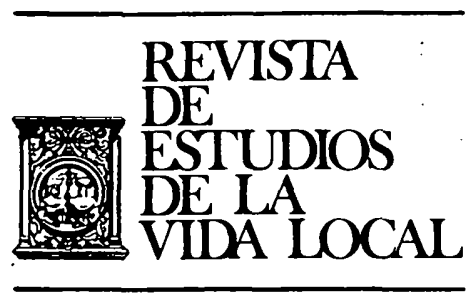

\section{CRONICAS}


REVL-1977, núm. 193. CORRAL GARCIA, ESTEBAN. LAS COMUNIDADES Y LA COMUNIDAD DE V... REVL-1977, núm. 193. CORRAL GARCIA, ESTEBAN. LAS COMUNIDADES Y LA COMUNIDAD DE V... 